\title{
PENGGUNAAN MOLUSISIDA JAYANTI DALAM MENGATASI HAMA KEONG MAS DI DESA BUNUT BAOK LOMBOK TENGAH
}

\author{
Oleh: \\ Suripto, Gunawan, E.R., Aryanti, E. \& Sukiman \\ Program Studi Biologi Fakultas MIPA Universitas Mataram
}

\begin{abstract}
ABSTRAK
Akibat serangan keong mas, produksi padi menurun hingga 30\% di beberapa tempat di Provinsi Nusa Tenggara Barat. Desa Bunut Baok Lombok Tengah adalah termasuk sentra penghasil padi yang mengalami gagal panen akibat serangan keong mas. Kegiatan penerapan iptek bagi masyarakat (IbM) untuk mengatasi masalah hama keong mas telah dilakukan di desa tersebut. Kegiatan IbM diawali dengan koordinasi Tim Pelasana IbM dengan Ketua Kelompok Tani Mohon Petunjuk di Desa Bunut Baok untuk memantapkan persiapan dan sosialisasi teknik pelasanaan IbM. Program IbM dilakukan dengan materi meliputi karakteristika tanaman jayanti (Sesbania sesban) dan cara pembudidayaannya, karakteristika jenis keong mas yang merupakan hama tanaman padi, cara penyiapan dan pembuatan bahan molusisida dari tanaman jayanti, dan aplikasinya untuk mengendalikan keong mas hama tanaman padi. Kegiatan IbM menggunakan berbagai media yang meliputi papan tulis, LCD, biji, dan specimen tanaman jayanti dewasa, serbuk kering daun jayanti, specimen keong mas hidup, air, dan alat-alat pertanian untuk pembuatan dan aplikasi molusisida di sawah padi. Metode yang digunakan meliputi ceramah, demonstrasi, pelatihan, dan diskusi. Kegiatan IbM diikuti oleh 12 orang anggota Kelompok Tani Mohon Petunjuk Desa Bunut Baok. Hasil yang dicapai adalah meliputi meningkatnya apresiasi petani terhadap tanaman jayanti, meningkatnya pengetahuan dan keterampilan petani dalam mengidentifikasi tanaman jayanti, terampil untuk membuat bahan molusisida dari tanaman jayanti, dan penggunaannya untuk mengendalikan keong mas hama tanaman padi.
\end{abstract}

Kata-kata kunci: Tanaman jayanti, keong mas hama tanaman padi, Desa Bunut Baok

\begin{abstract}
Fest of gold snail (keong mas) is the main factor of 30\% reduction of rice production in some parts of the Province of Nusa Tenggara Barat, including Bunut Baok Village in the District of Central Lombok. Iptek application for community activity (IACC) was done to solve the problem in Bunut Baok village. Coordination between team of IACC and the head of farmer group, Mohon Petunjuk in Bunut Baok village done first to make sure the plant and socialization thechnic activity of IACC. The IACC program done with course including characteristics and cultivication method of jayanti plant (Sesbania sesban) and characteristics of gold snail as a pest of rice plant. The media used for IACC activity were white board, LCD, seeds and specimen of adult jayanti plant, dray powder of jayanti leaf, life gold snail specimen, water, and farming tools to make and application of molluside in paddy field. Method for IACC activity were classroom talking, demonstration, exercise, and discussion. The participants of IACC activity were 12 person members of farmer group, Mohon Petunjuk Bunut Baok village. The result of this activity was improvement of farmer appreciation on jayanti plant, knowledge, and skill to make and applied anti mollusk from jayanti plant for controlling of gold snail, pest of rice plant.
\end{abstract}

Key words: Jayanti, gold snail, pest of rice plant, Bunut Baok village

Jurnal Biologi Tropis. Vol.13 No. 2 Juli 2013. 


\section{PENDAHULUAN}

$\mathrm{N}$ usa Tenggara Barat merupakan salah satu daerah penghasil beras yang cukup besar di Indonesia, namun demikian belakangan ini produksinya menurun. Penyebab penurunan produksi padi di daerah tersebut salah satunya adalah karena adanya gagal panen padi akibat serangan keong mas pada beberapa kawasan di propinsi tersebut (Suripto et al., 2005). Desa Bunut Baok di Lombok Tengah merupakan salah satu sentral kawasan sawah padi di Pulau Lombok, yang termasuk mengalami kegagalan panen padi akibat serangan keong mas.

Berbagai langkah penanggulangan hama keong mas di sawah padi telah dilakukan oleh petani, baik secara mekanik, biologis maupun kimiawi. Namun demikian, hasil-hasilnya dirasakan masih kurang efektif. Di Jawa Barat penggunaan molusisida dari bahan kimia sintetik, seperti Brestan sudah dilarang karena selain dapat mematikan tanaman padi juga dapat mematikan ikan-ikan di kolam yang airnya berasal dari irigasi sawah, sedangkan keong mas masih tetap hidup (Suripto, 2009 ${ }^{\mathrm{b}}$ ). Pengendalian keong mas secara mekanik dengan memasang tonggak-tonggak untuk untuk memerangkap telur keong mas dan pemungutan keong mas langsung oleh petani dirasakan kurang praktis, terutama untuk sawah padi yang sangat luas. Pengendalian keong mas secara biologis, seperti melepaskan hewan itik yang pernah dilakukan di Jawa Barat dan melepaskan hewan-hewan ternak babi seperti yang pernah dilakukan Bali juga tidak praktis, dan hanya dapat dilakukan pada lahan padi yang sudah dipanen atau pada lahan sebelum ditanami padi (Suripto, 1998). Pengendalian hama keong mas di sawah padi juga telah dilakukan oleh petani di Desa Bunut Baok, baik secara mekanik, biologis maupun kimiawi. Namun demikian, hasil-hasilnya dirasakan masih kurang efektif. Masyarakat petani di daerah tersebut saat ini hanya pasrah dan belum memiliki pengetahuan untuk memilih molusisida yang aman lingkungan.

Sebenarnya, bila masyarakat petani di daerah tersebut (setiap anggota dari kelompok tani memilki lahan padi sekurangkurangnya 10 are) mengetahui dan terampil untuk memilih, membuat dan mengaplikasikan bahan moluisida dari tumbuhan yang telah terbukti selektif untuk mematikan keong mas, maka masalah serangan keong mas terhadap tanaman padi di daerah tersebut akan dapat teratasi. Sehingga dengan demikian produktivitas padi sebagai komoditi unggulan di daerah tersebut akan dapat dipertahankan dan bahkan penghasilannya meningkat drastis karena berkurangnya kost untuk pengendalian. Tumbuhan sumber molusisida alami yang dimaksud adalah tanaman jayanti \{Sesbania sesban (L.) Merr. (Magnoliopsida: Fabaceae). Saat ini jenis tumbuhan tersebut di Desa Bunut Baok khususnya dan di Pulau Lombok pada umumnya tidak banyak dibudidayakan oleh para petani.

Hasil-hasil penelitian seleksi, evaluasi dan pengembangan kinerja anti moluska dari tanaman jayanti ( $S$. sesban) telah dicoba melalui program penerapan ilmu dan teknologi bagi masyarakat (IbM) petani padi untuk mengendalikan keong mas hama tanaman padi di Desa Bunut Baok Lombok Tengah. Tujuan dari kegiatan IbM tersebut adalah untuk meningkatkan apresiasi petani terhadap tanaman jayanti, meningkatkan keterampilan petani dalam pembuatan dan penggunaan molusisida dari tanaman jayanti untuk mengendalikan keong mas hama tanaman padi.

\section{BAHAN DAN METODE}

Pelaksanaan $\left(\mathrm{I}_{\mathrm{b}} \mathrm{M}\right)$ dilakukan dengan menggunakan pendekatan TOT (training of trainer), yaitu penyuluhan dan pelatihan bagi kelompok petani. Khalayak petani sebagai sasaran kegiatan adalah perwakilan petani 
dari setiap wilayah lingkungan (setingkat dusun) di Desa Bunut Baok Lmbok Tengah. Para wakil petani tersebut selanjutnya akan menjadi tutor bagi para anggota masingmasing kelompok tani setiap lingkungan. Materi kegiatan yang diberikan adalah ciri taksonomi dan ekologis tanaman jayanti, budidaya tanaman jayanati, teknologi produksi dan aplikasi molusisida yang feasible dari tanaman jayanti untuk mengendalikan keong mas hama tanaman padi. Habitus dan ciri organ reproduksi untuk identifikasi tanaman jayanti dapat dilihat pada Gambar 1.

Kegiatan IbM ini dilakukan dalam dua sesi, yaitu sesi teori dan sesi praktek. Dalam sesi teori. Metode yang digunakan adalah ceramah (media: diktat, papan tulis, dan LCD disediakan oleh tim) dan diskusi.
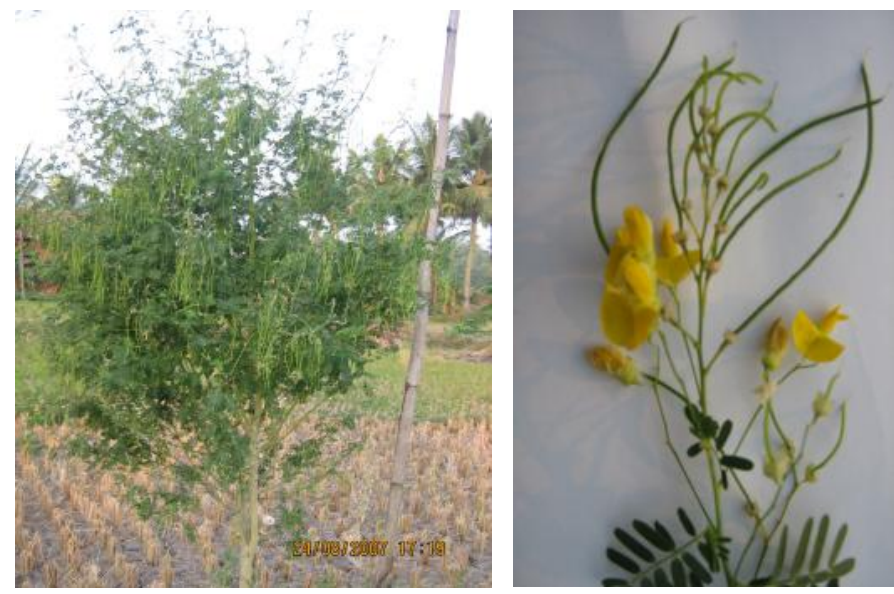

Gambar 1. Habitus dan organ reproduksi tanaman jayanti (Sesbania sesban)

Penyampaian materi juga diarahkan untuk meningkatkan apresisiasi petani terhadap tanaman jayanti sebagai sumber molusisida. Dalam sesi praktek, introduksi teknologi produksi dan aplikasi molusisida asal tanaman jayanti bagi petani diberikan dengan menggunakan metode demonstrasi dan praktek lapangan. Cara kerja pembuatan bahan molusisida dari tanaman jayanti dan aplikasinya untuk mengendalikan keong mas hama tanaman padi dapat dilihat pada Gambar 2 dan 3. 
Seleksi Tanaman Anti Moluska yang Memenuhi Syarat:

- Tersedia secara lokal, hasil bahan molusisida tinggi per tanaman pertahun

- Tidak bertentangan dengan keyakinan atau adat setempat

- Mudah dibudidaya oleh petani

- Bahan aktif mudah ditarik dengan bahan pelarut yang mudah didapat

- Bahan aktif sangat toksik terhadap organisme sasaran dan tidak toksik atau toksisitasnya sangat rendah terhadap organisme lainnya yang bukan sasaran

- Bahan molusisida yang dihasilkan tidak hilang potensinya selama penyimpanan sekurang-kurangnya satu tahun

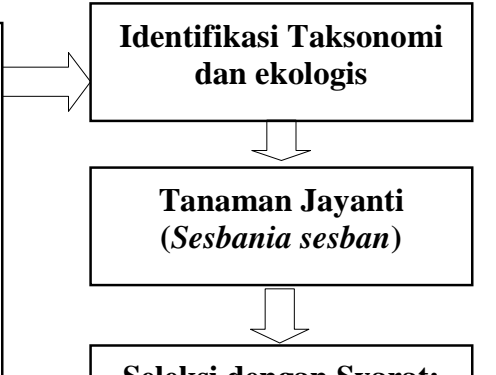

Seleksi dengan Syarat:

- Usia reproduksi

- Sehat dan bersih dari penyakit dan parasit

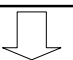

Koleksi Daun

- Bersih dari serasah

- Bagian dari urat daun majemuk dibuang

- Dengan cara diangin-anginkan dan digelar secara merata

- Dijaga agar tetap bersih, tidak terkena air dan tidak terkena sinar matahari secara langsung selama pengeringan
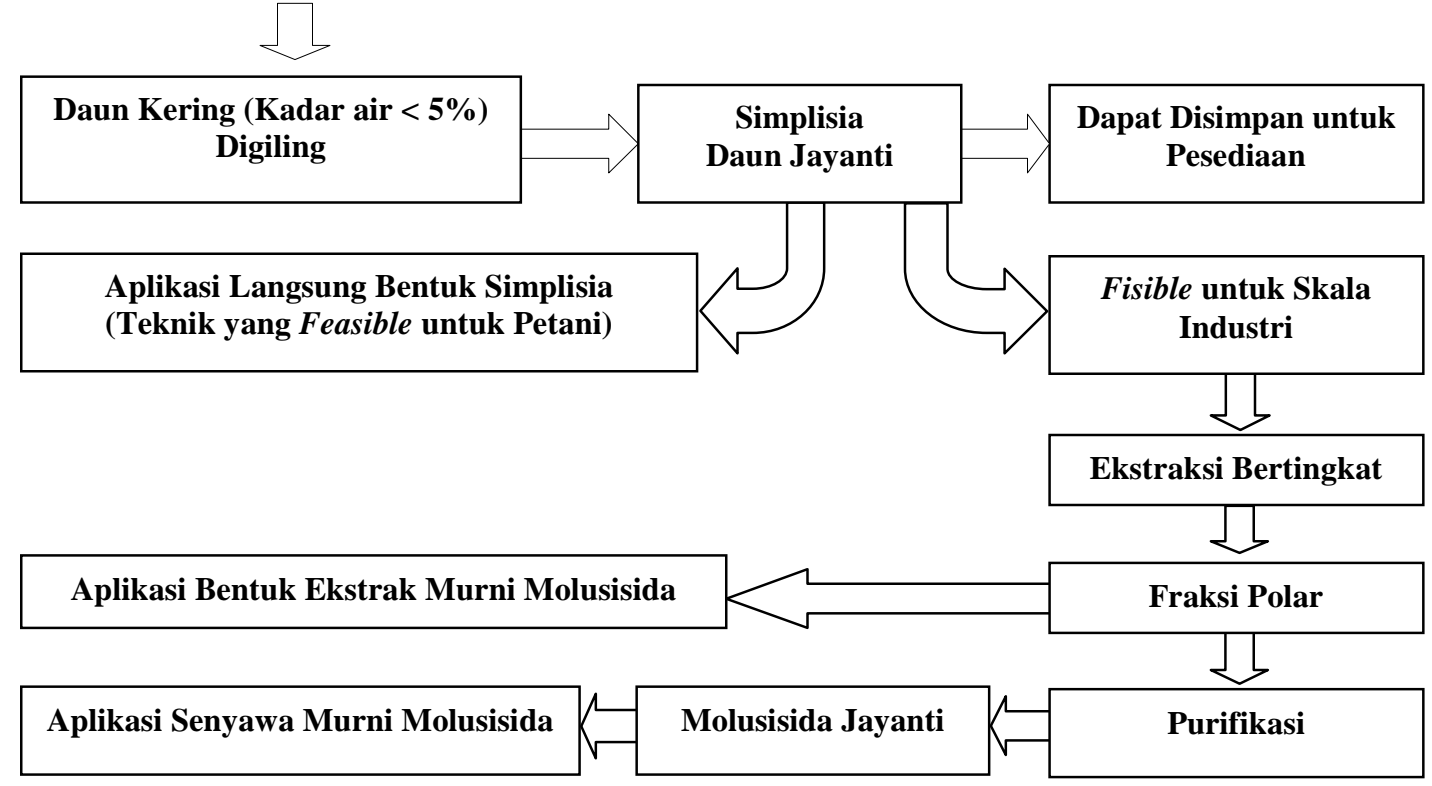

Gambar 2. Bagan alir kerja produksi bahan molusisida dari tanaman jayanti (Sesbania sesban) yang feasible bagi petani dan yang fisible untuk skala industri untuk mengendalikan keong mas hama tanaman padi.

Simplisia Daun Jayanti

( Dosis : 0,5 kg untuk areal $100 \mathrm{~m}^{2}$ yang sudah diinvasi atau untuk areal $200 \mathrm{~m}^{2}$ yang belum diinvasi keong mas )
Direndam dengan air bersih (10 liter) selama 12 jam sambil diaduk-aduk dalam interval setiap 3 jam 


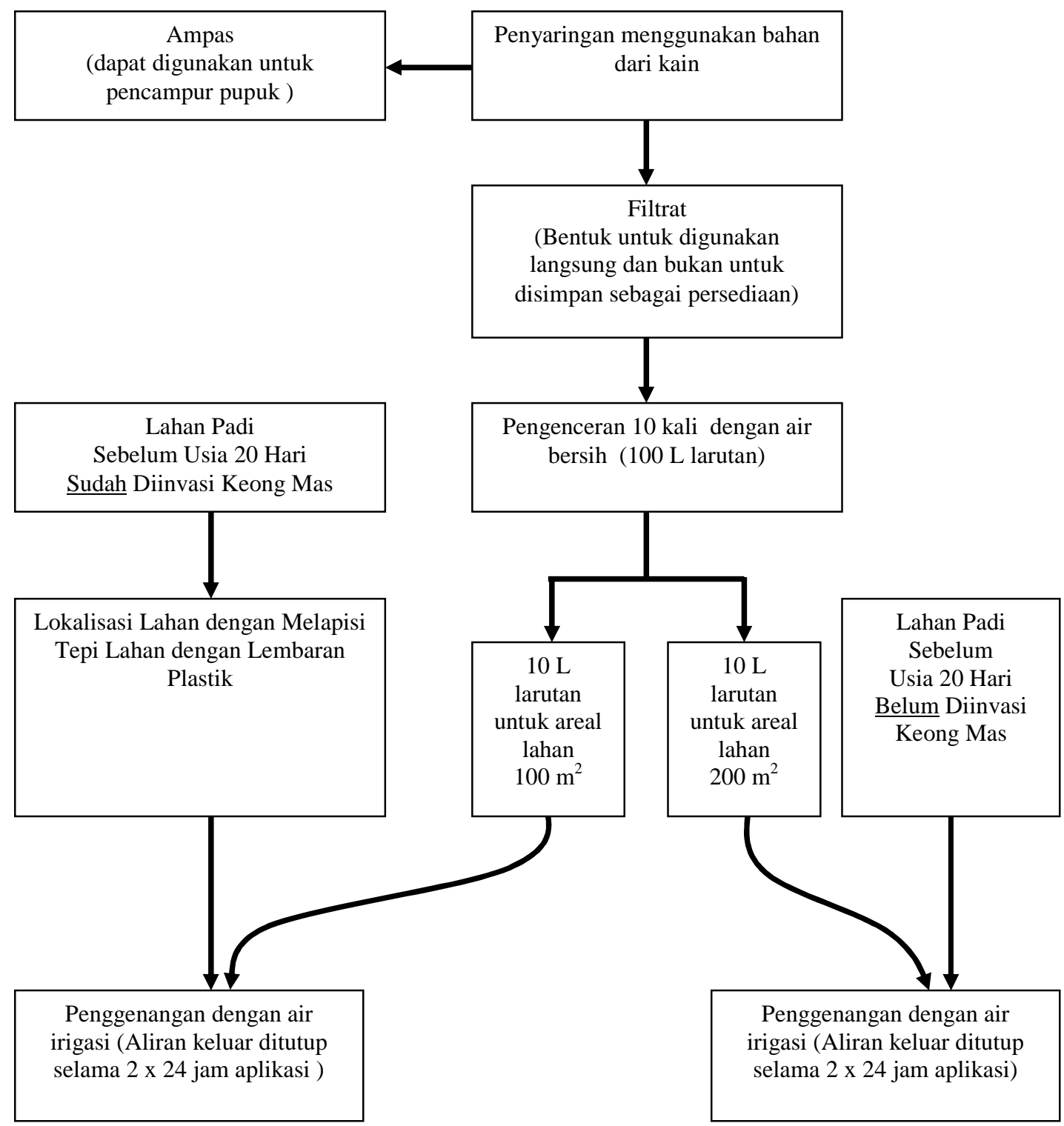

Gambar 3. Bagan alir kerja aplikasi simplisia daun jayanti (Sesbania sesban) untuk mengendalikan keong mas hama tanaman padi.

\section{HASIL DAN PEMBAHASAN}

A. Daya Anti Moluska dari Daun Jayanti Terhadap Keong Mas Hama Tanaman Padi Di Desa Bunut Baok Lombok Tengah
Uji coba daya anti moluska dari daun jayanti terhadap keong mas hama tanaman padi dilakukan dalam 10 unit ulangan percobaan oleh kelompok tani di Desa Bunut Baok Lombok Tengah. Bahan molusisida dari daun jayanti yang digunakan bervariasi menurut lama waktu penyimpanan larutan daun, yaitu 1) larutan daun yang langsung 
diaplikasikan, dan 2) larutan daun yang disimpan 24 jam sebelum diaplikasikan. Mortalitas keong mas diamati dalam dua periode aplikasi, 1) 24 jam dan 2) 48 jam pendedahan keong mas dalam larutan. Variasi konsentrasi larutan daun jayanti yang digunakan adalah 0 ppm sebagai kontrol dan 1 ppm (dari 1 gram kering daun dalam 1000 liter air) larutan daun jayanti.

Hasil menunjukkan, bahwa perlakuan 1 ppm larutan daun jayanti yang diaplikasikan secara langsung dapat mematikan 54\% keong mas setelah 24 jam perlakuan hingga $84 \%$ keong mas yang mati setelah 48 jam perlakuan (Gambar 4). Namun demikian, prosentase kematian keong mas ini menjadi lebih rendah bila larutan jayanti tersebut sebelumnya disimpan terlebih dahulu selama 24 jam sebelum diaplikasikan.

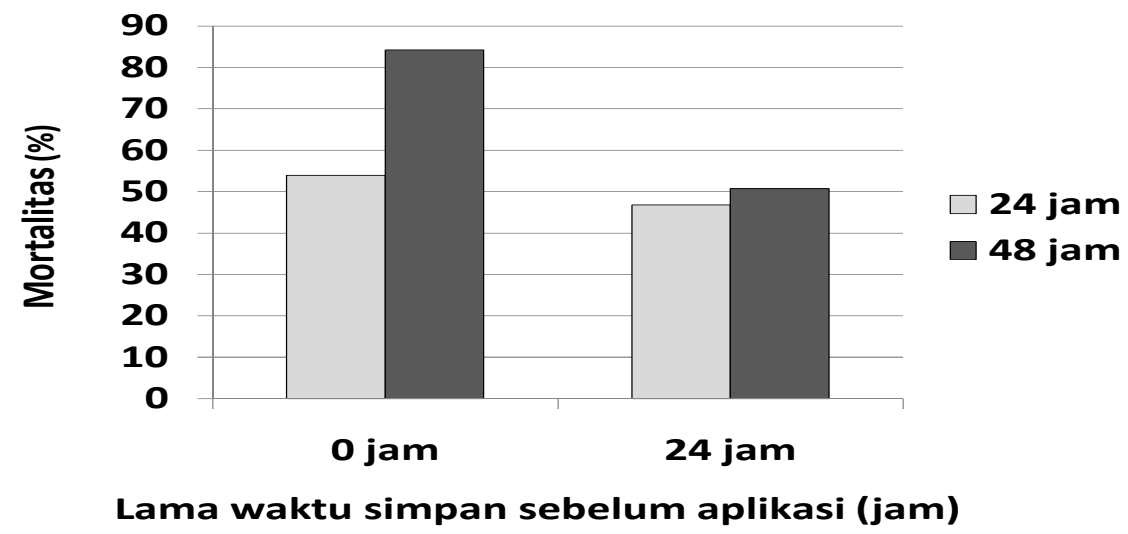

Gambar 4. Mortalitas keong mas pada perlakuan 1 ppm larutan daun jayanti

Bioaktivitas anti moluska dari larutan daun jayanti menurun karena kandungan aktifnya berupa saponin mengalami degradasi. Menurut Suripto (2011), kandungan aktif anti moluska dari tanaman jayanti dalam bentuk larutan daunnya akan menurun drastis setelah penyimpanan 24 jam sebelum diaplikasikan. Aktivitas anti moluska dari tanaman jayanti juga nyata menurun setelah penyimpanan selama satu bulan dalam bentuk pasta ekstrak. Demikian pula aktivitas anti moluska dari tanaman ini akan menurun setelah penyimpanan selama satu tahun dalam bentuk serbuk kering daunnya.

Berdasarkan hasil dan keterangan tersebut di atas, maka penggunaan molusisida dari tanaman jayanti dalam bentuk larutan sebaiknya langsung diaplikasikan tanpa disimpan terlebih dahulu. Bila diperlukan adanya penyimpanan bahan molusisida dari tanaman jayanti ini, maka penimpanan sebaiknya dilakukan terhadap bahan dalam bentuk serbuk kering daun untuk penyimpanan hingga maksimal satu tahun atau dalam bentuk pasta ekstrak untuk penyimpanan maksimal satu bulan.

\section{B. Pengetahuan dan Keterampilan Petani Membuat dan Menggunakan Molusisida dari Tanaman Jayanti untuk Mengendalikan Keong Mas Hama Tanaman Padi Di Desa Bunut Baok Lombok Tengah}

Berdasarkan hasil pre-test diketahui, bahwa sebelum kegiatan IbM ini dilaksanakan, para petani di Desa Bunut Baok Lombok Tengah belum mengetahui dan belum memiliki keterampilan dalam membuat dan mengaplikasikan bahan molusisida dari tanaman jayanti untuk 
mengendalikan keong mas hama tanaman padi. Setelah mengikuti kegiatan IbM ini, petani di Desa Bunut Baok Lombok Tengah memiliki kompetensi untuk mengidentifikasi tanaman jayanti, membuat dan mengaplikasikan bahan molusisida dari tanaman jayanti untuk mengendalikan keong mas hama tanaman padi (Tabel 1).
Kompetensi petani yang nyata dapat ditingkatkan dari hasil kegiatan IbM tersebut adalah meliputi kemampuan mengidentifikasi jenis tanaman jayanti, menseleksi ukuran dan usia tanaman jayanti yang cocok untuk dikoleksi daunnya, terampil mongeringanginkan daun jayanti, membuat larutan dan mengaplikasikannya dalam skala percobaan terhadap keong mas hama tanaman padi.

Tabel 1. Prosentase jumlah peserta menurut niilai kompetensi pembuatan dan aplikasi bahan molusisida dari tanaman jayanti untuk pengendalian keong mas hama tanaman padi pada kegiatan IbM Petani Padi yang Menghadapi Hama Keong Mas Di Desa Bunut Baok Lombok Tengah

\begin{tabular}{lccc}
\hline Kompetensi & \multicolumn{3}{c}{ Rentang Nilai (Skala 1 - 4) } \\
\cline { 2 - 4 } & $\begin{array}{c}2<\mathrm{x}<3 \\
\text { (Kurang) }\end{array}$ & $\begin{array}{c}3<\mathrm{x}<4 \\
\text { (Sedang) }\end{array}$ & $\begin{array}{c}4 \\
\text { (Baik) }\end{array}$ \\
\hline Idensifikasi jenis tanaman jayanti & $8,33 \%$ & $16,67 \%$ & $75 \%$ \\
Koleksi dan pengolahan bahan & $0 \%$ & $16,67 \%$ & $83,33 \%$ \\
Teknik aplikasi bahan molusisida & $8,33 \%$ & $8,33 \%$ & $83,33 \%$ \\
\hline
\end{tabular}

Pemahaman petani tentang jenis keong mas yang merupakan hama tanaman padi sangat diperlukan, agar langkah pengendalian oleh petani dapat dengan tepat mengenai sasaran. Di Indonesia keong mas yang menjadi hama tanaman padi teridentifikasi sebagai Pomacea canaliculata, dengan ciri utama warna cangkangnya kuning kusam, konde cangkangnya pendek, dan rumpun telurnya berwarna merah seperti buah murbai sehingga banyak petani yang menyebutnya keong murbai. Terdapat keong mas lain yang juga dapat dijumpai di Indonesia tetapi tidak menjadi hama terhadap tanaman padi, yang teridentifikasi sebagai Pomacea sp. (berbeda jenis dengan $P$. canaliculata) dengan ciri warna cangkangnya kuning cerah, konde cangkangnya tinggi, dan rumpun telurnya berwarna putih (Munandar, 2003).

Untuk meningkatkan efektivitas pengendalian keong hama tanaman padi, para petani juga perlu memiliki pengetahuan tentang spektrum tanaman inang dari keong mas tersebut. Selain padi, tanaman lain yang dapat diserang oleh keong mas adalah tanaman kangkung, dan semai tanaman jeruk (Mahfud, 1994 dalam Suripto, 2009 ${ }^{\mathrm{b}}$ ). Terhadap berbagai kultivar tanaman padi, keong mas menunjukkan kesukaan dan prefalensi yang tidak berbeda nyata menurut variasi kultivar tanaman padi tersebut, seperti yang telah diamati pada kultivar-kultivar padi Cibogo, Cigeulis dan Ciherang (Suripto, $2009^{\mathrm{b}}$ ).

Pengetahuan petani tentang stabilitas anti moluska dari bahan tanaman juga sangat diperlukan agar dalam pembuatan dan aplikasi bahan molusisida dari tanaman jayanti memperoleh hasil yang baik. Ujia hayati dalam skala laboratorium tentang stabilitas anti moluska dari tanaman jayanti terhadap keong mas pernah dilakukan oleh Suripto et al. (2008 dalam Suripto, 2011). Komponen aktif anti moluska dari daun $S$. sesban, dalam hal ini golongan saponin 
triterpen cukup stabil selama penyimpanan ekstrak selama satu bulan, namun kurang stabil selama penyimpanan dalam bentuk simplisia selama satu tahun, dan menjadi tidak aktif setelah dilarutkan dalam air selama 24 jam (Gambar 5).

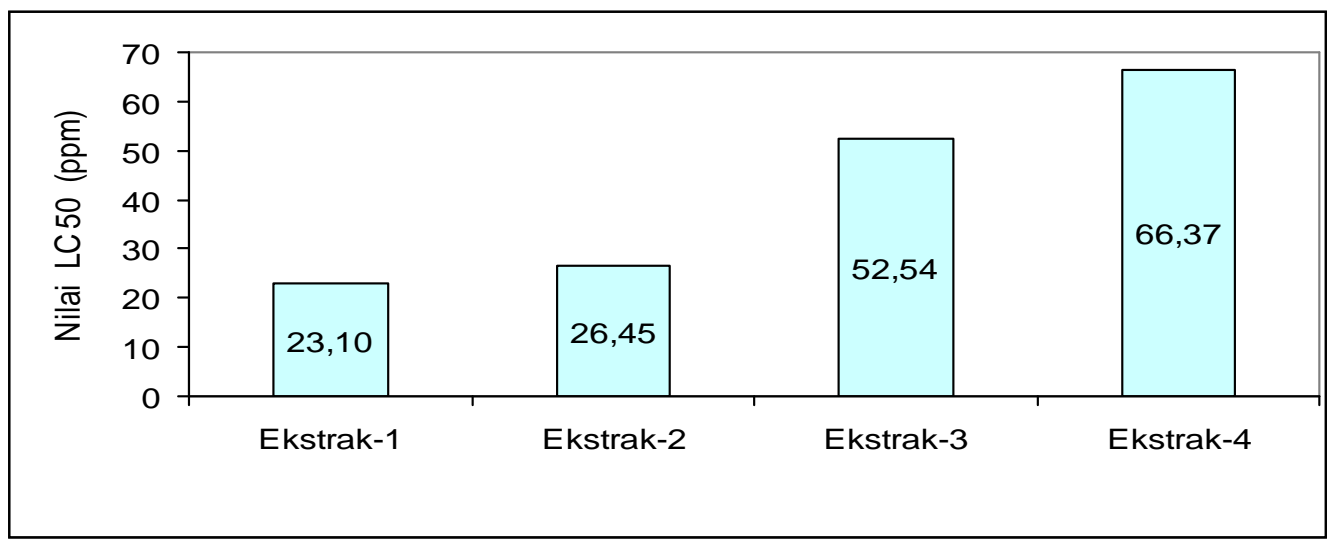

Gambar 5. Perbedaan toksisitas fraksi ekstrak-etanol dari daun tanaman jayanti menurut variasi bentuk penyimpanan (Penyimpanan simplisia sebelum diekstraksi dan penyimpanan ekstrak sebelum diaplikasi) (Sumber : Suripto, 2011)

\section{Keterangan:}

- Ekstrak-1 adalah ekstrak yang langsung diaplikasikan berasal dari simplisia yang langsung diekstraksi

- Ekstrak-2 adalah ekstrak yang disimpan satu bulan sebelum aplikasi berasal dari simplisia yang langsung diekstraksi.

- Ekstrak-3 adalah ekstrak yang langsung diaplikasikan berasal dari simplisia yang disimpan satu tahu nsebelum diekstraksi .

- Ekstrak-3 adalah ekstrak yang disimpan satu bulan sebelum aplikasi berasal dari simplisia yang disimpan satu tahun sebelum diekstraksi .

Pada laporan lain juga dikemukakan, bahwa kandungan senyawa dari golongan saponin triterpen akan stabil selama tidak dalam larutan dengan air, tetapi bioaktivitasnya akan segera hilang setelah sekurang-kurangnya 24 jam berada dalam air (Francis et al., 2002; Suripto, 2009 ${ }^{\mathrm{a}}$ ). Berdasarkan hasil-hasil tersebut dapat direkomendasikan, bahwa penyimpanan simplisia daun jayanti sebelum diekstraksi sebaiknya tidak melebihi satu tahun, sedangkan penyimpanan bentuk ekstrak sebelum digunakan tidak melebihi satu bulan. Komponen aktif anti moluska dari daun jayanti, dalam hal ini saponin triterpen adalah tidak stabil dalam air. Selama aplikasi setelah 24 jam kandungan bahan anti moluska ekstrak tersebut tidak aktif lagi (tidak toksik letal terhadap keong mas).

\section{Apresiasi Petani Desa Bunut Baok Lombok Tengah Terhadap Tanaman Jayanti}

Sebelum dilaksanakan IbM ini, petani di Desa Bunut Baok Lombok Tengah tidak memilik apresiasi yang memadai terhadap tanaman jayanti. Hal ini karena selain tidak mengenal lebih banyak tentang identitas serta ciri dari tanaman jayanti, para petani juga tidak memiliki pengetahuan tentang manfaat tanaman jayanti sebagai sumber bahan molusisida yang dapat digunakan untuk 
mengendalikan keong mas hama tanaman padi. Para petani hanya mengetahui bahwa daun tanaman jayanti tidak dapat dimakan seperti daun turi, kayunya tidak banyak, dan kanopinya tidak besar dan tidak rimbun sehingga tidak menarik untuk dijadikan sebagai pohon pelindung di sawah. Dengan demikian, sehingga para petani selama ini tidak memiliki minat untuk mengembangkan tanaman jayanti sebagai tanaman pelindung di sawahnya. Berdasarkan hasil survey langsung dan hasil wawancara dengan petani, di Desa Bunut Baok tidak dapat dijumpai adanya tanaman jayanti baik di sawah maupun di pekarangan rumah. Menurut Suripto $\left(2009^{\mathrm{a}}\right)$, di Pulau Lombok Nusa Tenggara Barat tanaman jayanti baru dapat diketemukan keberadaannya dengan kemelimpahan sedang di daerah pesawahan di Desa Gondang Lombok Utara, sedangkan di Pulau Sumbawa, tanaman jayanti baru dapat dijumpai keberadannya sebagai tanaman liar di daerah rawa di Jereweh Sumbawa Barat, dan oleh petani setempat, tanaman jayanti ini disebut sebagai turi rawa.

$$
\text { Setelah kegiatan IbM ini }
$$
dilaksanakan, petani Desa Bunut Baok Lombok Tengah memiliki apresiasi yang tinggi terhadap tanaman jayanti sebagai tanaman sumber bahan molusisida untuk pengendalian keong mas hama tanaman padi. Para petani juga memiliki minat untuk mengembangkan tanaman tersebut sebagai tanaman pelindung di sawahnya. Hal ini terbukti dari tingginya skor minat petani akan pengemabngan tanaman jayanti hasil wawancara dan dari besarnya prosentase jumlah petani yang melaksanakan penanaman bibit jayanti dengan menggunakan anakan dan biji jayanti yang diperoleh pada kegiatan IbM ini. Kegiatan IbM ini juga menghasilkan luaran berupa 1) Buku Panduan Pembuatan dan Penggunaan Molusisida Jayanti untuk Pengendalian Keong Mas Hama Tanaman Padi, 2) draf artikel ilmiah, 3) semai jayanti yang ditumbuhan dari biji oleh petani, dan 3) pengembangan diktat mata kuliah Ekologi Tumbuhan.

\section{KESIMPULAN}

Dalam skala percobaan, 1 ppm larutan daun jayanti terbukti efektif mematikan keong mas dan fesible bagi petani Desa Bunut Lombok Tengah untuk mengendalikan keong mas hama tanaman padi. Kegiatan IbM telah meningkatkan apresiasi petani di Desa Bunut Baok terhadap tanaman jayanti, meningkatkan pengetahuan dan keterampilan petani dalam pembuatan dan aplikasi bahan molusisida dari tanaman jayanti untuk mengendalikan keong mas hama tanaman padi.

\section{DAFTAR PUSTAKA}

Francis,G., Kerem, Z., Makkar, H.P.S. \& K. Becker (2002). The biological action of saponins in animal systems: A review. British J. of Nutrition. 88: 587-605.

Munandar, A. (2003). Serba-serbi Keong Murbei dan Keong Mas. Laporan tidak dipublikasikan. Balai Penelitian dan Pengembangan Zoologi. LIPI. Bogor.

Suripto (1998). Evaluasi sifat anti moluska dari tanaman jayanti (Sesbania sesban). J. Gema Rinjani. 3(3):22-27.

Suripto $\left(2009^{\mathrm{a}}\right)$. Selektivitas anti moluska dari tanaman jayanti \{Sesbania sesban (L.) Merr.\} J. Biologi Tropis. 10(1): 24-32.

Suripto $\left(2009^{\mathrm{b}}\right)$. Preferensi dan kecepatan makan dari keong mas terhadap tanaman padi. PIJAR MIPA. 4(2): 80-84. 
Penggunaan Molusisida ..................

Suripto (2011). Stabilitas anti moluska dari tanaman jayanti \{Sesbania sesban (L.) Merr.\} Oryza. 7(7): 19-27.

Suripto, Jupri, A. \& G. Tresnani (2005). Spektrum efek toksik dari berbagai fraksi ekstrak daun jayanti (Sesbania sesban) terhadap keong mas hama tanaman padi. J. Biologi Tropis. 8(1): 15-20. 